\title{
Effect of lung function and mode of inhalation on penetration of aerosol into the human lung
}

\author{
DEMETRI PAVIA ${ }^{1}$, MAURICE L. THOMSON ${ }^{2}$, STEWART W. CLARKE ${ }^{1}$, AND \\ HARRY S. SHANNON ${ }^{2}$
}

From the Department of Thoracic Medicine, The Royal Free Hospital, London NW3 $2 Q G^{1}$, and the TUC Centenary Institute of Occupational Health, London School of Hygiene and Tropical Medicine, London WC1E $7 \mathrm{HT}^{2}$

\begin{abstract}
Pavia, D., Thomson, M. L., Clarke, S. W., and Shannon, H. S. (1977). Thorax, 32, 194-197. Effect of lung function and mode of inhalation on penetration of aerosol into the human lung. The method using radioactive tracer particles has been applied to study the effect of the mode of inhalation of aerosols on the depth of deposition in the lungs of 50 patients with airways obstruction. The findings show that the penetration of particles is directly related to: (1) volume inspired per breath $\left(\mathrm{V}_{\mathrm{I}}\right) ;(2)$ forced expiratory volume in one second $\left(\mathrm{FEV}_{1}\right)$; and inversely related to (3) flow rate during inhalation $(\dot{V})$. In mathematical terms, alveolar deposition $(\%)=$ $40.3\left(\mathrm{~V}_{\mathrm{I}}\right)+10.98\left(\mathrm{FEV}_{1}\right)-0.75(\dot{\mathrm{V}})+40 \cdot 4$; for this regression $\mathrm{F}=4.41$ and $\mathrm{P}<0.01$.
\end{abstract}

Topical administration of drugs into the bronchial tree by inhalation of aerosol often has advantages over the oral and parenteral routes, particularly in patients with reversible airways obstruction. The dose is relatively small (Lal et al., 1972) and response may be more rapid (Plit et al., 1972). The main benefit of this route, however, is that high levels of the drug are concentrated at the site of action in the lung, giving the desired therapeutic action while minimising undesired systemic side effects.

The efficacy of topical therapy depends on the proportion of the inhaled drug which is deposited in the lung (Blackwell et al., 1974) and, for certain drugs, that proportion that is retained in the more peripheral parts (Godfrey et al., 1974). Some of the factors which determine penetrance of aerosol have long been known to particle physicists (Hatch and Gross, 1964). Recent findings indicate the importance of the technique of inhalation (Booker et al., 1967; Goldberg and Lourenço, 1973) and the effect of lung and especially airway abnormality (Thomson and Short, 1969; Pavia et al., 1977) in reducing the penetrance of aerosol.

We report a study on 50 patients with varying degrees of airways obstruction who inhaled monodisperse $5 \mu \mathrm{m}$ aerodynamic particles in a controlled manner. The mode of inhalation was based on that suggested for inhaling therapeutic pressurised aerosol. Predicted values have been obtained of the tracheobronchial/alveolar partition ratios for those particles deposited in the lungs, taking into accoun the mode of inhalation and the degree of airway? obstruction.

\section{Method}

The tracer technique used here to assess depth of deposition and clearance of inhaled particles io humans has been fully reported by Thomson et al. (1974). Polystyrene particles $(5 \pm 0.7 \mu \mathrm{m})$ were generated by a spinning disc (May, 1949) and inhaled via the mouth of the patients seated uprighte The particles were tagged unleachably (Few et al. 1970) with the gamma-emitting radionuclide teeh netium-99m $(99 \mathrm{~m} \mathrm{Tc})$. The volume inspired in 8 single breath $\left(\mathrm{V}_{\mathrm{I}}\right), \mathbf{0} \cdot 11,0.30,0.50,0.75$ or 0.88 litre was randomly allocated to each patient and deter: mined by an automatic valve. After inspiration there was an obligatory 3-second breath-holding pause before exhalation. The average flow rate during inhalation was measured by a pneumotacho? graph. The mean, range, and standard deviatios (SD) of the flow rate during inhalation (V) for the 4\$ patients for whom measurements were available were $25 \cdot 4(13 \cdot 3-50 \cdot 4 ; \mathrm{SD} \pm 7 \cdot 9) \mathrm{l} / \mathrm{min}$. Immediatel after inhalation the patients washed out theif mouths and then swallowed some water to remove radioaerosol from the oropharynx and oesophagus. $\stackrel{\perp}{\varrho}$

Immediately afterwards and six hours later gamme radiation from the patients' lungs was counted by 
two horizontally opposed scintillation detectors, one in contact with the midpoint of the sternum anteriorly and the other against the spine axially opposite to the first. The degree of collimation was such that the field of view of the detectors included most of both lungs but virtually excluded the stomach. In all runs the first count was normalised to $100 \%$ to adjust for unavoidable differences in the initial radioactive lung burden; the burden did not exceed $30 \mu \mathrm{Ci}$ in any one run. The initial and six-hour counts were corrected for radioactive decay and background, and the second was expressed as a percentage of the initial count after inhalation. It is estimated that in $90 \%$ of the population (Thomson and Short, 1969; Foord et al., 1975) the mucociliary clearance phase (tracheobronchial clearance) will be over or nearing completion after six hours and the percentage of the particles remaining in the lung at six hours $(6 \mathrm{~h} \%$ Ret) is used here as a measure of alveolar deposition.

The forced expiratory volume in one second $\left(F_{1}\right)$ and forced vital capacity (FVC) of the patients were measured by a dry bellows spirometer (Vitalograph ${ }^{\circledR}$ ) before the inhalation of the tracer particles. The patients were under continuous observation and did not smoke for one hour prior to the inhalation of the tracer particles nor during the six-hour experimental period.

\section{Patients}

Fifty male patients with varying degrees of airways obstruction volunteered for the study. All but two of these were smokers. Their mean age was 65.3 years (range 43-85; SD \pm 8.9 ), mean height 1.68 metres (range 1.51-1.83; $\mathrm{SD} \pm 0.08$ ), and tobacco consumption 47.8 pack-years (range $3.5-255 \cdot 1$; SD士 $42 \cdot 1)$. The Table gives the ventilatory capacities of the 50 patients.

Table Means, ranges, and standard deviations of the ventilatory capacities for 50 patients

\begin{tabular}{|c|c|c|c|c|c|}
\hline & \multicolumn{2}{|l|}{$F E V_{1}$} & \multicolumn{2}{|l|}{$F V C$} & \multirow{2}{*}{$\begin{array}{l}F E V_{1} / F V C \\
\text { Obs }(\%)\end{array}$} \\
\hline & Obs. & $\%$ Pred. & Obs. & $\%$ Pred. & \\
\hline $\begin{array}{l}\text { Mean } \\
\text { Range } \\
\text { SD }\end{array}$ & $\begin{array}{l}1.07 \\
0.44-2.32 \\
0.49\end{array}$ & $\begin{array}{l}38 \cdot 6 \\
16-88 \\
17 \cdot 8\end{array}$ & $\begin{array}{l}2 \cdot 38 \\
1.07-3.93 \\
0.73\end{array}$ & $\begin{array}{l}64 \cdot 2 \\
26-115 \\
17 \cdot 8\end{array}$ & $\begin{array}{l}45 \cdot 0 \\
23-73 \\
12 \cdot 8\end{array}$ \\
\hline
\end{tabular}

\section{Results}

There was a significant relationship between the percentage of particles retained at six hours and three variables, namely, $V_{I}, F E V_{1}$, and $\dot{V}$. $V_{I}$ and $F V_{1}$ accounted for $19 \%$ of the variation in the regression and $\dot{V}$ for a further $6 \%$. The way in which these three variables affect the $6 \mathrm{~h} \%$ Ret is given by the equation $6 \mathrm{~h} \%$ Ret $=40 \cdot 3\left(\mathrm{~V}_{\mathrm{I}}\right)+$ $10.98\left(\mathrm{FEV}_{1}\right)-0.75(\dot{\mathrm{V}})+40.4 ; \mathrm{F}=4.41, \mathrm{P}<0.01$.

Thus for the ranges of variables investigated alveolar deposition will increase by $\mathbf{4 0} \%$ for every 1 litre increase in $V_{I}$ and by $11 \%$ for every 1 litre increase in $\mathrm{FEV}_{\mathrm{I}}$ but will decrease by $0.75 \%$ for every $1 \mathrm{litre} / \mathrm{min}$ increase in flow rate. (The $t$ values for the regression coefficients of $V_{1}, F E V_{1}$, and $\dot{V}$ were $3.18(P<0.005), 1.94 \quad(P \approx 0.05)$, and 1.92 $(P \approx 0.05)$ respectively).

The Figure shows a nomogram for estimating the effect of $V_{I}$ and $F E V_{1}$ on alveolar deposition for single breaths of aerosol inhaled at a normal flow rate of $30 \mathrm{l} / \mathrm{min}$.

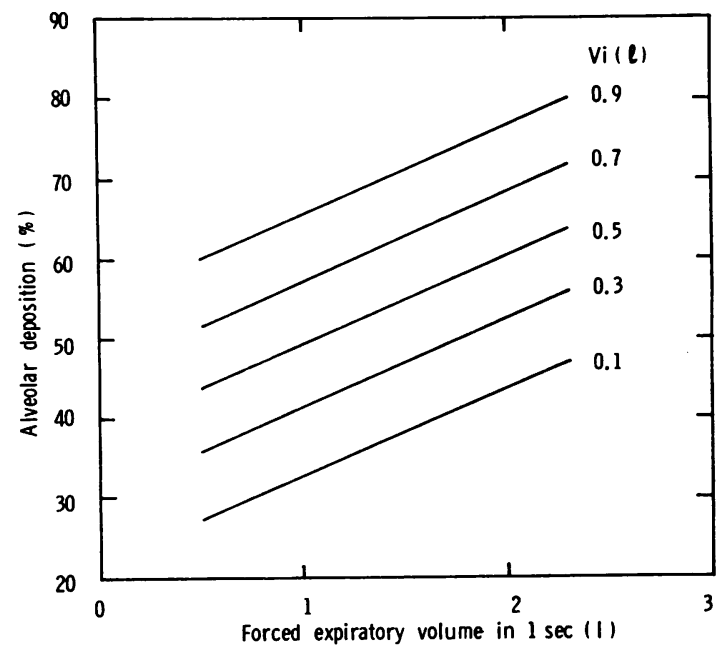

Figure Nomogram for predicting alveolar deposition of $5 \mu \mathrm{m}$ particles as a percentage of total lung deposition $(S D \pm 18.5 \%)$ for various inspired volumes $\left(V_{I}\right)$ taken at a flow rate of $30 \mathrm{l} / \mathrm{min}$.

\section{Discussion}

In our experience, sex, age, height, and long-term tobacco smoking do not affect mucociliary clearance rates as measured by the above method (Pavia et al., 1970; Pavia and Thomson, 1970; Thomson and Pavia, 1973).

The figures quoted above are for the alveolar deposition as a percentage of the total deposition in the lung which is about $85 \%$ of that inhaled for the monodisperse particles used here. For heterodisperse aerosols from pressurised canisters total deposition is much lower, amounting to about $10 \%$ for isoprenaline (Blackwell et al., 1974). However, the 
factors controlling penetration within the lung will be similar for both types of aerosol.

The site of deposition of inhaled aerosols in the human lung depends on the physical characteristics of the aerosol, the mode of inhalation, and the degree of abnormality of the airways. In general, the bigger the aerodynamic diameter (diameter $\times$ density ${ }^{1 / 2}$ ), the nearer to the mouth will the deposition of the aerosol be (Lippmann and Albert, 1969; Pavia and Thomson, 1976). The main inhalation variables that affect the depth of deposition are the flow rate during inhalation, which, if high, reduces penetrance by impaction (Lippmann and Albert, 1969; Goldberg and Lourenço, 1973), and the tidal volume, which, if increased, will increase penetrance provided the flow rate is constant (Pavia et al., 1977). A breath holding pause after inhalation of the aerosol favours gravity settlement of a small proportion of particles which would otherwise remain airborne during expiration. It has recently been shown that airways obstruction and, to a lesser degree, restrictive defect cause premature deposition during inhalation; this is presumably due to increase in impaction caused by disturbed flow in these conditions (Thomson and Short, 1969; Lippmann et al., 1970; Goldberg and Lourenço, 1973; Thomson and Pavia, 1974; Dolovich et al., 1976).

However sophisticated the technique of administration, aerosol deposition while maximum in one zone will spread along the airways on either side. Thus it is not possible to deposit drugs in the fine airways without some deposition in the alveoli and in the large airways.

The effect of particle size and flow rate on lung penetration has been known for years but appears to have been neglected in makers' recommendations for therapeutic aerosol administration. For example, patients may be advised to direct the aerosol jet from pressure nebulisers towards the pharynx while inhaling. This results in impaction of most of the heterodisperse aerosol on the mouth and pharynx so that only the smallest particles (10-20\% of the dose) are likely to reach the lung. Of that which reaches the lung much may then be deposited in the large airways and be ineffective if the site of action is deeper in the lung. Godfrey et al. (1974) have demonstrated that sodium cromoglycate is more effective in controlling exercise-induced asthma when administered in 2 as compared to $10 \mu \mathrm{m}$ particle sizes, presumably because more of the smaller particles reach the site of action of the drug: this is assumed to be in the small airways.

In the same way the efficacy of topical steroid administration may well depend on the aerosol reaching the small airways. Some of the steroid preparations found to be unsuccessful for topical administration may have failed for no other reason $\vec{F}$ than that the depth of deposition in the lung was inadequate.

The above results suggest that to enhance depth of $\frac{\overline{\bar{D}}}{\bar{N}}$ deposition of therapeutic aerosols in the lungs full $\vec{\sigma}$ breaths of the aerosol should be inhaled slowly 0 followed by a breath-holding pause which 'freezes' some particles at the furthest point of penetration. $\overrightarrow{0}$ For pressure nebulisers total deposition will be enhanced if the bulk of the aerosol is in small particles $\vec{\omega}$ $(2-7 \mu \mathrm{m})$ and is dispersed in a container in which the particles lose their momentum before being inhaled. $x$ Control of the distribution of aerosols in the lung is $\underset{N}{\omega}$ likely to become increasingly important as more information is obtained about the site of action of $\overrightarrow{0}$ drugs.

\section{References}

Blackwell, E. W., Briant, R. H., Conolly, M. E., Davies, D. S., and Dollery, C. T. (1974). Metabolism of $\varphi$ isoprenaline after aerosol and direct intrabronchial. administration in man and dog. British Journal of $\square$ Pharmacology, 50, 587-591.

Booker, D. V., Chamberlain, A. C., Rundo, J., Muir, D. C. F., and Thomson, M. L. (1967). Elimination of $5 \mu$ particles from the human lung. Nature, 215, 30-33. $\frac{\mathrm{O}}{\mathrm{Q}}$

Cotes, J. E. (1975). Lung Function, 3rd edition. Blackwell @ Scientific Publications, Oxford.

Dolovich, M. B., Sanchis, J., Rossman, C., and Newhouse, $\frac{\mathrm{O}}{3}$ M. T. (1976). Aerosol penetrance: a sensitive index of peripheral airways obstruction. Journal of Applied Physiology, 40, 468-471.

Few, J. D., Short, M. D., and Thomson, M. L. (1970). 음 Preparation of $99 \mathrm{~m}$ Tc labelled particles for aerosol studies. Radiochemical and Radioanalytical Letters, $5, \stackrel{\times}{\circ}$ 275.

Foord, N., Black, A., and Walsh, M. (1975). Pulmonary deposition of inhaled particles with diameters in the $\frac{O}{3}$ range 2.5 to $7.5 \mu \mathrm{m}$. In 4th International Symposium on Inhaled Particles and Vapours, edited by W. H. Walton. 은

Unwin, Old Woking, Surrey.
Godfrey, S., Zeidifard, E., Brown, K., and Bell, J. H. (1974). The possible site of action of sodium cromoglycate assessed by exercise challenge. Clinical Science and Molecular Medicine, 46, 265-272.

Goldberg, I. S. and Lourenço, R. V. (1973). Deposition of aerosols in pulmonary disease. Archives of Internal ${ }^{\mathrm{W}}$ Medicine, 131, 88-91.

Hatch, T. F. and Gross, P. (1964). Pulmonary Depositionco and Retention of Inhaled Aerosols. Academic Press, $\frac{\overparen{D}}{\mathscr{D}}$ London and New York.

Lal, S., Harris, D. M., Bhalla, K. K., Singhal, S. N., and Butler, A. G. (1972). Comparison of beclomethasone $\overline{0}$ diproprionate aerosol and prednisolone in reversible $\overrightarrow{\mathbb{D}}$ airways obstruction. British Medical Journal, $3, \frac{\varrho}{\Phi}$
314-320.

Lippmann, M. and Albert, R. E. (1969). The effect of particle size on the regional deposition of inhaled 
aerosols in the human respiratory tract. American Industrial Hygiene Association Journal, 30, 257-275.

Lippmann, M., Albert, R. E., and Peterson, H. T., Jr. (1970). The regional deposition of inhaled aerosols in man. In Inhaled Particles III, edited by W. H. Walton, p. 105. Unwin, Old Woking, Surrey.

May, K. R. (1949). An improved spinning top homogeneous spray apparatus. Journal of Applied Physics, 20, 932-938.

Pavia, D., Short, M. D., and Thomson, M. L. (1970). No demonstrable long term effects of cigarette smoking on the mucociliary mechanism of the human lung. Nature, 226, 1228-1231.

Pavia, D. and Thomson, M. L. (1970). Unimpaired mucociliary clearance in the lung of a centenarian smoker (Letter). Lancet, 2, 101-102.

Pavia, D. and Thomson, M. L. (1976). The fractional deposition of inhaled 2 and 5 micron particles in the alveolar and tracheobronchial regions of the healthy human lung. Annals of Occupational Hygiene, 19, 109-114.

Pavia, D., Thomson, M. L., and Shannon, H. S. (1977). The effect of airway obstruction and tidal volume of aerosol inhaled on the depth of deposition in the human lung. Archives of Environmental Health. (In press).

Plit, M., Goldman, H. I., Cassel, M. L., and Zwi, S. (1972). The bronchodilator action of fenoterol (Berotec) in asthma. Medical Proceedings, 18, 41.

Thomson, M. L. and Pavia, D. (1973). Long-term tobacco smoking and mucociliary clearance. Archives of Environmental Health, 26, 86-89.

Thomson, M. L. and Pavia, D. (1974). Particle penetration and clearance in the human lung. Archives of Environmental Health, 29, 214-219.

Thomson, M. L., Pavia, D., Gregg, I., and Stark, J. E. (1974). Bromhexine and mucociliary clearance in chronic bronchitis. British Journal of Diseases of the Chest, 68, 21-27.

Thomson, M. L. and Short, M. D. (1969). Mucociliary function in health, chronic obstructive airway disease, and asbestosis. Journal of Applied Physiology, 26, 535-539.

Requests for reprints to: Dr Demetri Pavia, Department of Thoracic Medicine, The Royal Free Hospital, Pond Street, Hampstead, London NW3 2QG. 